\title{
Phase I study of combination chemotherapy with irinotecan hydrochloride and nedaplatin for cervical squamous cell carcinoma: Japanese Gynecologic Oncology Group study
}

\author{
KAICHIRO YAMAMOTO ${ }^{1}$, KATSUJI KOKAWA ${ }^{2}$, NAOHIKO UMESAKI ${ }^{3}$, \\ RYUICHIRO NISHIMURA ${ }^{4}$, KAZUO HASEGAWA $^{5}$, IKUO KONISHI ${ }^{6}$, FUMITAKA SAJI $^{7}$, \\ MASATO NISHIDA $^{8}$, HIROSHI NOGUCHI ${ }^{9}$ and KEN TAKIZAWA ${ }^{10}$
}

\begin{abstract}
${ }^{1}$ Department of Obstetrics and Gynecology, Sakai Hospital, Kinki University School of Medicine, 2-7-1 Harayamadai, Minami-ku, Sakai, Osaka 590-0132; ${ }^{2}$ Kokawa Clinic, 366-4 Musota; ${ }^{3}$ Department of Obstetrics and Gynecology, Wakayama Medical University, 811-1 Kimiidera, Wakayama 641-0012; ${ }^{4}$ Department of Gynecologic Oncology, Hyogo Cancer Center, 13-70 Kitaoji-cho, Akashi, Hyogo 673-8558; ${ }^{5}$ Inamino Hospital, 423-2 Tsuchiyama Azakawaike, Hiraoka-cho, Kakogawa, Hyogo 675-0104; ${ }^{6}$ Department of Gynecology and Obstetrics, Kyoto University Graduate School of Medicine, 54 Shogoin Kawahara-cho, Sakyo-ku, Kyoto 606-8507; ${ }^{7}$ National Hospital Organization Kure Medical Center, 3-1 Aoyama-cho, Kure, Hiroshima 737-0023; ${ }^{8}$ National Hospital Organization Kasumigaura Medical Center, 2-7-14 Shimotakatsu, Tsuchiura, Ibaraki 300-8585; ${ }^{9}$ National Hospital Organization Matsumoto Medical Center, 1209 Yoshikawamurai-cho, Matsumoto, Nagano 399-8701; ${ }^{10}$ Department of Gynecology, Cancer Institute Hospital, Japanese Foundation for Cancer Research, 3-10-6 Ariake, Koto-ku, Tokyo 135-8550, Japan
\end{abstract}

Received December 10, 2008; Accepted February 9, 2009

DOI: 10.3892/or_00000316

\begin{abstract}
The aim of this study (JGOG1063) was to determine the recommended dose (RD) for combination chemotherapy with irinotecan hydrochloride (CPT-11) and nedaplatin (NDP) for advanced cervical squamous cell carcinoma. CPT-11 was given intravenously in fixed doses of $60 \mathrm{mg} / \mathrm{m}^{2}$ on days 1 and 8 and NDP, in escalating doses, on day 1 , every 4 weeks. A total of 15 patients were enrolled in the study. At level 1 (NDP: $50 \mathrm{mg} / \mathrm{m}^{2}$ ), one of the 3 patients developed grade 3 diarrhea, so 3 additional patients were enrolled at this level. As none of the 3 additional patients exhibited dose-limiting toxicity, level 1 was elevated to level 2 (NDP: $60 \mathrm{mg} / \mathrm{m}^{2}$ ). The maximum tolerated dose was not reached, even at the highest dose level (level 4; NDP: $80 \mathrm{mg} / \mathrm{m}^{2}$ ). No further dose escalation was carried out, and level 4 (CPT-11: $60 \mathrm{mg} / \mathrm{m}^{2}$, NDP: $80 \mathrm{mg} / \mathrm{m}^{2}$ ) was determined as the RD.
\end{abstract}

Correspondence to: Dr Kaichiro Yamamoto, Department of Obstetrics and Gynecology, Sakai Hospital, Kinki University School of Medicine, 2-7-1, Harayamadai, Minami-ku Sakai, Osaka 590-0132, Japan

E-mail: yamamoto@sakai.med.kindai.ac.jp

Key words: irinotecan hydrochloride, nedaplatin, phase I study, cervical cancer, squamous cell carcinoma

\section{Introduction}

Radiotherapy has been shown to be effective in the treatment of cervical squamous cell carcinoma, whereas response to chemotherapy has not been so positive. The efficacy of cisplatin (CDDP), however, has been rated highly in terms of response rate since it was first introduced in the clinical treatment of cervical carcinoma (1). A number of CDDP-based chemotherapy regimens have been developed, including BOMP (bleomycin, vincristine, mitomycin $\mathrm{C}$ and cisplatin) (2) and IP (ifosfamide and cisplatin) (3). However, as yet, none of these regimens have yielded satisfactory results and new regimens are urgently needed.

Irinotecan hydrochloride (CPT-11) is a DNA topoisomerase I inhibitor developed in Japan. In a late phase II study in patients with cervical carcinoma, it exhibited relatively high efficacy, with a response rate of $23 \%$ (4). Sugiyama et al (5) reported that administration of CPT-11 $\left(60 \mathrm{mg} / \mathrm{m}^{2}\right)$ on days 1,8 and 15 with $\operatorname{CDDP}\left(60 \mathrm{mg} / \mathrm{m}^{2}\right)$ on day 1 yielded a response rate of $59 \%$ in cases of advanced or recurrent cervical cancer and $78 \%$ in cases in which this regimen was applied as a neoadjuvant chemotherapy for advanced cervical carcinoma (6).

Nedaplatin (NDP) is a second-generation platinum compound developed in Japan. When tested in vitro using a human gynecologic cancer cell line, NDP exerted stronger antitumor activity than CDDP (7). In a phase II study of NDP in patients with cervical carcinoma, the response rate was $46.3 \%$ (19/41) (8), suggesting that the antitumor activity of NDP is comparable to, or stronger than, that of CDDP (response rate: $35.9 \%, 14 / 39$ ) (9). Furthermore, since NDP is 
less nephrotoxic than CDDP, it can even be used in patients with compromised renal function such as those with hydronephrosis; and as administration requires no fluid replacement, it can even be administered in outpatients. For these reasons, the potential of NDP in the treatment of cervical carcinoma is now beginning to draw keen interest.

Among preclinical studies on combined CPT-11 and platinum therapy, one in vitro study using a human non-small cell cancer cell line (PC-14) revealed that the synergistic effect of NDP + CPT-11 was stronger than that of CDDP + CPT-11 (10). This suggested that combination treatment with CPT-11 and NDP had potential as a therapy regimen.

Therefore, the Japanese Gynecologic Oncology Group (JGOG, Head: Kiichiro Noda) Cervical Cancer Committee initiated a phase I study to determine the recommended dose (RD) for combination CPT-11 + NDP treatment, with the goal of developing a new regimen of therapy for advanced cervical squamous cell carcinoma (a type of cancer prone to complications such as hydronephrosis and hydroureter, resulting in compromise of renal function). Higher response rates are also expected for this regimen than those with conventional CPT-11 + CDDP therapy.

\section{Patients and methods}

Prior approval for the study was obtained from the Institutional Review Board (IRB) of each participating facility. Patients who provided informed consent in writing and satisfied the eligibility criteria shown below were enrolled in the study.

Eligibility criteria. Histologically proven squamous cell cervical carcinoma; presence of measurable lesions not required; no prior chemotherapy; eligible for chemotherapy; 75 years of age or younger; Eastern Cooperative Oncology Group (ECOG) performance status 0-2; white blood cell count of $\geq 4,000 / \mathrm{mm}^{3}$ and $\leq 12,000 / \mathrm{mm}^{3}$; platelet count of $\geq 100,000 / \mathrm{mm}^{3}$; hemoglobin, $\geq 9.5 \mathrm{~g} / \mathrm{dl}$; AST (aspartate aminotransferase, GOT) and ALT (alanine aminotransferase, GPT), both less than twice the normal level at each facility; total bilirubin, $\leq 1.5 \mathrm{mg} / \mathrm{dl}$; creatinine clearance of $\geq 60 \mathrm{ml} / \mathrm{min}$; and serum creatinine level of $\leq 1.5$ times the criterion level at each facility; expected survival of $\geq 3$ months; written informed consent.

Patients meeting any of the criteria below were excluded from the study.

Exclusion criteria. An active infection or other serious medical condition such as bowel obstruction, ileus, interstitial pneumonia or pulmonary fibrosis, uncontrollable diabetes mellitus, heart failure, renal failure, and hepatic failure; diarrhea or watery stool; massive pleural, peritoneal, or pericardial effusion; brain metastasis requiring treatment; active double cancer; pregnant or breast-feeding women, and women unwilling to use contraception; a history of serious reactions or hypersensitivity to drugs; patients judged inappropriate by the investigator for entry into the study for any reason related to safety.

Drug administration. CPT-11 was administered on days 1 and 8 , and NDP on day 1 at the dose levels specified below.
Table I. Dose escalation schedule.

\begin{tabular}{lcccc}
\hline $\begin{array}{c}\text { Level } \\
\left(\mathrm{mg} / \mathrm{m}^{2}\right)\end{array}$ & $\begin{array}{c}\text { Irinotecan } \\
\left(\mathrm{mg} / \mathrm{mg}^{2}\right)\end{array}$ & $\begin{array}{c}\text { No. of } \\
\text { patients }\end{array}$ & $\begin{array}{c}\text { No. of patients } \\
\text { with DLT }\end{array}$ \\
\hline 1 & 60 & 50 & 6 & 1 \\
2 & 60 & 60 & 3 & 0 \\
3 & 60 & 70 & 3 & 0 \\
4 & 60 & 80 & 3 & 0 \\
\hline
\end{tabular}

A 3-week interval was interposed between each course of treatment.

CPT-11, in fixed doses of $60 \mathrm{mg} / \mathrm{m}^{2}$ diluted with $500 \mathrm{ml}$ normal saline, glucose, or electrolyte fluid, was given intravenously $\geq 90 \mathrm{~min}$ on days 1 and 8 ; and NDP, in $300 \mathrm{ml}$ or more of normal saline, was given intravenously $\geq 60 \mathrm{~min}$ on day 1 , every 4 weeks.

Study design. Dose escalation was performed as described in Table I. NDP was started at $50 \mathrm{mg} / \mathrm{m}^{2}$ (level 1), followed by $60 \mathrm{mg} / \mathrm{m}^{2}$ (level 2), $70 \mathrm{mg} / \mathrm{m}^{2}$ (level 3) and $80 \mathrm{mg} / \mathrm{m}^{2}$ (level 4). Between 3 and 6 patients were included in the group at each dose level, and dose-limiting toxicity (DLT) was evaluated only in the first course of treatment. DLT was defined as follows: (1) grade 4 leukopenia $\left(<1,000 / \mathrm{mm}^{3}\right)$ or neutropenia $\left(<500 / \mathrm{mm}^{3}\right)$, rated according to NCI-CTC (ver. 2) of the Japan Clinical Oncology Group (JCOG), lasting for 5 days or more, despite treatment with G-CSF; (2) grade 3 or higher leukopenia $\left(<2,000 / \mathrm{mm}^{3}\right)$ or neutropenia $\left(<1,000 / \mathrm{mm}^{3}\right)$ with fever of $38.5^{\circ} \mathrm{C}$ or above; (3) grade 4 thrombocytopenia $\left(<25,000 / \mathrm{mm}^{3}\right)$; (4) grade 3 thrombocytopenia $\left(<50,000 / \mathrm{mm}^{3}\right)$ accompanied by severe hemorrhagic symptoms; or (5) grade 3 or higher adverse drug events other than those described above, diarrhea, nausea/vomiting, anorexia, and alopecia. Diarrhea was rated grade 3 where frequency of evacuation increased to 7-9 times per day with moderate or severer abdominal pain, and grade 4 where frequency of evacuation increased to 10 or more times per day and/or hemorrhagic diarrhea was noted.

If none of the initial 3 patients in a group showed DLTs, dosage was raised to the next level. If one or two of the 3 patients experienced DLTs, then 3 additional patients were enrolled at the same dose level, bringing the total to 6 patients for that dose level. If 2 or fewer of the 6 patients experienced DLTs, dosage was raised to the next level. If 3 or more of the 6 patients, or all 3 of the initial 3 patients experienced DLTs, that dose level was considered the maximum tolerated dose (MTD) and the dose one level lower than the MTD was considered the RD.

Antitumor efficacy was evaluated in accordance with the Criteria for Direct Efficacy Evaluation of Gynecologic Cancer Chemotherapy prepared by the Japan Society of Clinical Oncology.

\section{Results}

Patients and treatment. A total of 15 patients registered between January 2002 and March 2004 at Kinki University 
Table II. Patient characteristics $(n=15)$.

\begin{tabular}{lc} 
Age (years) & \\
Median & 57 \\
Range & $30-69$ \\
WHO PS & \\
0 & 11 \\
1 & 4 \\
FIGO stage & \\
Ib & 6 \\
IIa & 1 \\
IIb & 2 \\
IIIb & 4 \\
IVb & 1 \\
Recurrent & 1 \\
Prior therapy & \\
None & \\
Surgery & 10 \\
\hline
\end{tabular}

Sakai Hospital and Wakayama Medical University were enrolled in the study. The background variables of the eligible patients are summarized in Table II. Median age was 57 years (range: 30-69). Performance status (PS) was 0 in 11 patients and 1 in 4 patients. Stages were Ib, IIa, IIb, IIIb, IVb and recurrence in $6,1,2,4,1$ and 1 patient, respectively. Of the 15 patients, 5 had received prior treatment (surgery in all cases), while 10 had received no prior treatment.

Ten patients received one course of treatment and the remaining 5 received 2 courses of treatment. Table I shows the number of patients enrolled at each dose level and the number of patients exhibiting DLTs. At level 1, one of the 3 patients developed grade 3 diarrhea, so 3 additional patients were enrolled at this level. As none of the 3 additional patients exhibited DLTs, level 1 was elevated to level 2. The MTD was not reached, even at the highest dose level (level 4). No further dose escalation was carried out and level 4 was determined as the RD.

Toxicity profiles. Tables III and IV summarize adverse reactions observed in the first and total courses of treatment for the 15 patients. Analysis of hematologic toxicity during the first course of treatment revealed that incidence was highest for leukopenia $(73 \%, 11 / 15)$, followed by anemia $(60 \%, 9 / 15)$, neutropenia $(40 \%, 6 / 15)$ and thrombocytopenia $(20 \%, 3 / 15)$. All of these adverse reactions were grade 3 or lower. Analysis of total courses of treatment revealed grade 4 thrombocytopenia in one patient at level 2. Among non-hematologic toxicities during the first course of treatment, incidence was highest for diarrhea $(53 \%, 8 / 15)$, followed by nausea/vomiting $(27 \%$, $4 / 15)$, anorexia $(20 \%, 3 / 15)$, and alopecia $(20 \%, 3 / 15)$. No patient developed renal dysfunction. Adverse reactions of grade 3 or higher were confined to grade 3 diarrhea and nausea/vomiting, observed in one patient at level 1. At level 2, on analysis of total courses of treatment, grade 3 diarrhea was noted in one patient. At level 4, on analysis of total courses of treatment, no patient exhibited grade 4 hematologic toxicity or grade 3 or higher non-hematologic toxicity. No treatment-associated death was recorded. Treatment on day 8 was skipped due to adverse reactions in one $(7 \%)$ of the 15 patients.

Antitumor efficacy. Of the 9 patients included in the analyses of tumor response, 7 exhibited partial response (PR), with a response rate of $78 \%$ (Table V). The other 2 patients exhibited minor response (MR) and progressive disease (PD). Responses were thus noted at all dose levels.

Table III. Hematological toxicity.

\begin{tabular}{|c|c|c|c|c|c|c|c|c|c|c|c|c|c|c|c|c|c|}
\hline \multirow{2}{*}{$\begin{array}{l}\text { Dose } \\
\text { Level }\end{array}$} & \multicolumn{4}{|c|}{ Leukopenia } & \multicolumn{4}{|c|}{ Neutropenia } & \multicolumn{4}{|c|}{ Anemia } & \multicolumn{4}{|c|}{ Thrombocytopenia } & \multirow{2}{*}{$\begin{array}{c}\begin{array}{c}\text { Toxicity } \\
(\%)\end{array} \\
\text { G4 }\end{array}$} \\
\hline & G1 & $\mathrm{G} 2$ & G3 & G4 & G1 & $\mathrm{G} 2$ & G3 & G4 & G1 & G2 & G3 & G4 & G1 & $\mathrm{G} 2$ & G3 & G4 & \\
\hline \multicolumn{18}{|l|}{ First course } \\
\hline $1(n=6)$ & 4 & 1 & 0 & 0 & 1 & 0 & 1 & 0 & 1 & 2 & 0 & 0 & 1 & 0 & 0 & 0 & 0 \\
\hline $2(n=3)$ & 0 & 2 & 1 & 0 & 0 & 0 & 2 & 0 & 3 & 0 & 0 & 0 & 1 & 0 & 0 & 0 & 0 \\
\hline $3(n=3)$ & 0 & 1 & 0 & 0 & 0 & 0 & 0 & 0 & 1 & 0 & 0 & 0 & 0 & 0 & 0 & 0 & 0 \\
\hline $4(n=3)$ & 0 & 1 & 1 & 0 & 0 & 1 & 1 & 0 & 1 & 1 & 0 & 0 & 0 & 0 & 1 & 0 & 0 \\
\hline Total $(n=15)$ & 4 & 5 & 2 & 0 & 1 & 1 & 4 & 0 & 6 & 3 & 0 & 0 & 2 & 0 & 1 & 0 & - \\
\hline \multicolumn{18}{|l|}{ Total course } \\
\hline $1($ course $=7)$ & 5 & 1 & 0 & 0 & 1 & 1 & 1 & 0 & 1 & 2 & 0 & 0 & 2 & 0 & 0 & 0 & - \\
\hline $2($ course $=5)$ & 0 & 3 & 2 & 0 & 0 & 0 & 4 & 0 & 4 & 1 & 0 & 0 & 1 & 0 & 0 & 1 & - \\
\hline $3($ course $=3)$ & 0 & 1 & 0 & 1 & 0 & 0 & 0 & 0 & 1 & 0 & 0 & 0 & 0 & 0 & 0 & 0 & - \\
\hline $4($ course $=5)$ & 0 & 2 & 2 & 0 & 0 & 2 & 2 & 0 & 2 & 2 & 0 & 0 & 0 & 0 & 1 & 0 & - \\
\hline Total $($ course $=20)$ & 5 & 7 & 4 & 0 & 1 & 3 & 7 & 0 & 8 & 5 & 0 & 0 & 3 & 0 & 1 & 1 & - \\
\hline
\end{tabular}


Table IV. Non-hematologic toxicity.

\begin{tabular}{|c|c|c|c|c|c|c|c|c|c|c|c|c|c|c|c|c|c|}
\hline \multirow{2}{*}{$\begin{array}{l}\text { Dose } \\
\text { Level }\end{array}$} & \multicolumn{4}{|c|}{ Diarrhea } & \multicolumn{4}{|c|}{$\begin{array}{c}\text { Nausea } \\
\text { vomiting }\end{array}$} & \multicolumn{4}{|c|}{ Anorexia } & \multicolumn{4}{|c|}{ Alopecia } & \multirow{2}{*}{$\begin{array}{c}\text { Toxicity } \\
(\%) \\
\text { G4 }\end{array}$} \\
\hline & G1 & $\mathrm{G} 2$ & G3 & G4 & G1 & $\mathrm{G} 2$ & G3 & G4 & G1 & $\mathrm{G} 2$ & G3 & G4 & G1 & $\mathrm{G} 2$ & G3 & G4 & \\
\hline \multicolumn{18}{|l|}{ First course } \\
\hline $1(n=6)$ & 0 & 1 & 1 & 0 & 0 & 1 & 1 & - & 1 & 0 & 0 & - & 0 & 0 & 0 & - & 17 \\
\hline $2(n=3)$ & 0 & 3 & 0 & 0 & 1 & 0 & 0 & - & 1 & 0 & 0 & - & 2 & 0 & 0 & - & 0 \\
\hline $3(n=3)$ & 1 & 0 & 0 & 0 & 0 & 0 & 0 & - & 0 & 0 & 0 & - & 1 & 0 & 0 & - & 0 \\
\hline $4(n=3)$ & 1 & 1 & 0 & 0 & 1 & 0 & 0 & - & 1 & 0 & 0 & - & 0 & 0 & 0 & - & 0 \\
\hline Total $(\mathrm{n}=15)$ & 2 & 5 & 1 & 0 & 2 & 1 & 1 & - & 3 & 0 & 0 & - & 3 & 0 & 0 & - & - \\
\hline \multicolumn{18}{|l|}{ Total course } \\
\hline $1($ course $=7)$ & 0 & 1 & 1 & 0 & 0 & 1 & 1 & - & 1 & 0 & 0 & - & 0 & 0 & 0 & - & - \\
\hline $2($ course $=5)$ & 0 & 3 & 1 & 0 & 1 & 0 & 0 & - & 1 & 0 & 0 & - & 2 & 0 & 0 & - & - \\
\hline $3($ course $=3)$ & 1 & 0 & 0 & 0 & 0 & 0 & 0 & - & 0 & 0 & 0 & - & 1 & 0 & 0 & - & - \\
\hline $4($ course $=5)$ & 2 & 1 & 0 & 0 & 2 & 0 & 0 & - & 2 & 0 & 0 & - & 1 & 0 & 0 & - & - \\
\hline Total $($ course $=20)$ & 3 & 5 & 2 & 0 & 3 & 1 & 1 & - & 4 & 0 & 0 & - & 4 & 0 & 0 & - & - \\
\hline
\end{tabular}

Table V. Treatment outcome.

\begin{tabular}{lcccccc}
\hline Level & CR & PR & MR & NC & PD & CR+PR (\%) \\
\hline $1(n=4)$ & 0 & 3 & 1 & 0 & 0 & 3 \\
$2(n=1)$ & 0 & 1 & 0 & 0 & 0 & 1 \\
$3(n=2)$ & 0 & 1 & 0 & 0 & 1 & 1 \\
$4(n=2)$ & 0 & 2 & 0 & 0 & 0 & 2 \\
Total $(n=9)$ & 0 & 7 & 1 & 0 & 1 & $7 / 9(78 \%)$ \\
\hline
\end{tabular}

$\mathrm{CR}$, complete response; $\mathrm{PR}$, partial response; $\mathrm{MR}$, minor response; $\mathrm{NC}$, no change and $\mathrm{PD}$, progressive disease.

\section{Discussion}

Sugiyama et al $(5,6)$ reported that patients with cervical carcinoma treated with CPT-11 $\left(60 \mathrm{mg} / \mathrm{m}^{2}\right)$ on days 1,8 and 15 and CDDP $\left(60 \mathrm{mg} / \mathrm{m}^{2}\right)$ on day 1 showed response rates of $59 \%$ for advanced/recurrent carcinoma and $78 \%$ in NAC for locally advanced cervical carcinoma. In their study, however, treatment with CPT-11 on days 8 and 15 had to be skipped in a high percentage $(31 \%)$ of patients. Bearing these earlier findings in mind, we decided to administer CPT-11 on days 1 and 8 in this study to minimize skips and maintain dose intensity. Phase I/II studies were conducted on combined CPT-11 and NDP treatment in patients with advanced nonsmall cell lung cancer (Noda K, et al, Proc ASCO 21: abs. $313,2002)$. In the phase I study, the initial NDP dose level was set at $50 \mathrm{mg} / \mathrm{m}^{2}$ and the highest dose level was 100 $\mathrm{mg} / \mathrm{m}^{2}$ (equivalent to the recommended dose level for uncombined NDP treatment). DLTs were noted in one case each at NDP dose levels of 50, 60 and $70 \mathrm{mg} / \mathrm{m}^{2}$, whereas no DLT was observed at dose levels of 80 and $90 \mathrm{mg} / \mathrm{m}^{2}$. At the highest dose level $\left(100 \mathrm{mg} / \mathrm{m}^{2}\right)$, one patient exhibited DLTs, but the MTD was not reached. On the basis of these findings, the recommended dose level was set at $60 \mathrm{mg} / \mathrm{m}^{2}$ for CPT-11 and $100 \mathrm{mg} / \mathrm{m}^{2}$ for NDP. As DLTs had already been observed at the initial NDP dose level $\left(50 \mathrm{mg} / \mathrm{m}^{2}\right)$, this level was used as the initial NDP dose level in this study. Noda et al (11) reported that the rate of response to uncombined NDP treatment $\left(80 \mathrm{mg} / \mathrm{m}^{2}\right)$ for cervical carcinoma was $34.2 \%$. This rate was comparable to that $(46.3 \%)$ reported by Kato et al (8) for uncombined NDP treatment $\left(100 \mathrm{mg} / \mathrm{m}^{2}\right)$. Furthermore, in the same study, Noda et al (11) noted that the incidences of grade 3 or 4 thrombocytopenia and leukopenia, which are DLTs of NDP, were relatively low (13.5 and 18.9\%, respectively). Therefore, in this study, the highest NDP dose level was set at $80 \mathrm{mg} / \mathrm{m}^{2}$. This dose level corresponds to the low end of the dose range approved for uncombined NDP treatment. The dose level of CPT-11 in this study was set at $60 \mathrm{mg} / \mathrm{m}^{2}$, since in a domestic dose-finding study of CPT-11 and carboplatin in patients with non-small cell lung carcinoma (12), grade 4 diarrhea (a DLT) was noted in 2 of 6 patients following combined CPT-11 $\left(70 \mathrm{mg} / \mathrm{m}^{2}\right)$ and platinum treatment.

With the regimen in this study, signs of hematologic toxicity included leukopenia $(73 \%)$, anemia (60\%), thrombocytopenia ( $40 \%)$, and neutropenia (20\%), although all of these were grade 3 or lower. As signs of non-hematologic toxicity, grade 3 diarrhea and nausea/vomiting were noted in only one patient, for whom treatment on day 8 had to be skipped. At dose level 4 , no grade 4 hematologic toxicity or grade 3 or higher non-hematologic toxicity was noted in any course of treatment. In the present study, one patient exhibited DLTs at dose level 1, but no further DLT was noted at any higher dose level up to level 4, and the MTD was not reached. Therefore, we set level 4 as the RD. No nephrotoxicity was observed, either. These findings indicate that this regimen is tolerable enough to enable maintenance of the planned dose intensity. Two studies have been published concerning phase I studies of this particular combination chemotherapy for cervical carcinoma. Machida et al (13) reported that the RD was $50 \mathrm{mg} /$ 
$\mathrm{m}^{2}$ (days 1,8 and 15 ) for CPT-11 and $60 \mathrm{mg} / \mathrm{m}^{2}$ (day 1) for NDP and Tsuda et al (14) reported it as $50 \mathrm{mg} / \mathrm{m}^{2}$ (day 1) for CPT-11 and $80 \mathrm{mg} / \mathrm{m}^{2}$ (day 1) for NDP. The findings of the present study are quite similar to those reported by Machida et al (13). However, when compared to that reported by Tsuda et al (14), the dose level of CPT-11 was higher in the present study. This difference in CPT-11 dose level was probably a result of differences in patient histories: the patients in the present study were completely free of a history of prior chemotherapy or radiotherapy, whereas $56 \%$ of the patients studied by Tsuda et al (14) had received chemotherapy or radiotherapy prior to the study. We believe that the RD determined in the present study is acceptable for neoadjuvant chemotherapy in patients with no history of prior treatment. Although the number of patients included in evaluation of antitumor efficacy was not large, 7 of the 9 patients exhibited $\mathrm{PR}$, with a response rate of $78 \%$. This rate is as high as those reported by Sugiyama et al (5) (78\%) and Chitapanarux et al (15) $(67 \%)$. The usefulness of combined CPT-11 and NDP treatment for cervical carcinoma was also endorsed by the in vitro study by Yamamoto et al (16).

In conclusion, for combined CPT-11 and NDP treatment of previously untreated cervical carcinoma, the recommended doses for CPT-11 and NDP were determined to be $60 \mathrm{mg} / \mathrm{m}^{2}$ (days 1 and 8 ) and $80 \mathrm{mg} / \mathrm{m}^{2}$ (day 1), respectively. This regimen is expected to be tolerable and highly effective in patients with cervical carcinoma. The JGOG Cervical Cancer Committee has carried out a phase II study of this regimen for cervical carcinoma at the recommended dose.

\section{References}

1. Bonomi P, Blessing JA and Stehman FB: Randomized trial of three cisplatin dose schedules in squamous cell carcinoma of the cervix: a Gynecologic Oncology Group study. J Clin Oncol 3: 1079-1085, 1985.

2. Souhami L, Gil RA, Allan SE, Canary PC, Araujo CM, Pinto LH and Silveira TR: Randomized trial of chemotherapy followed by pelvic radiation therapy in Stage IIIB carcinoma of the cervix. J Clin Oncol 9: 970-977, 1991.

3. Omura GA, Blessing JA, Vaccarello L, Berman ML, ClakePearson DL, Mutch DG and Anderson B: Randomized trial of cisplatin versus cisplatin plus mitolactol versus cisplatin plus ifosfamide in advanced squamous carcinoma of the cervix: a Gynecologic Oncology Group study. J Clin Oncol 15: 165-171, 1997.
4. Takeuchi S, Dobashi K, Fujimoto S, et al: A late phase II study of CPT-11 on uterine cervical cancer and ovarian cancer. Jpn J Cancer Chemother 18: 1681-1689, 1991.

5. Sugiyama T, Yakushiji M, Noda K, et al: Phase II study of irinotecan and cisplatin as first-line chemotherapy in advanced or recurrent cervical cancer. Oncology 58: 31-37, 2000.

6. Sugiyama T, Nishida T, Kumagai S, et al: Combination therapy with irinotecan and cisplatin as neoadjuvant chemotherapy in locally advanced cervical cancer. Br J Cancer 81: 95-98, 1999.

7. Nguyen HN, Sevin BU, Averette HE, Perrars J, Ramos R, Angiolt R and Ochiai K: Comparison of cytotoxicity and cell kinetic perturbations of five platinum compounds in gynecologic cancer cell lines. Int J Oncol 3: 375-382, 1993.

8. Kato T, Nishimura H, Yakushiji M, Noda K, Terashima Y and Takeuchi S: Phase II study of 254-S (cis-diammine glycolato platinum) for gynecological cancer. Jpn J Cancer Chemother 19: 695-701, 1992.

9. Noda K, Takeuchi S, Kurihara S, et al: Phase II study of cisplatin in cervical and endometrial carcinomas. Jpn J Cancer Chemother 14: 1129-1135, 1987.

10. Kanzawa F, Koizumi F, Koh Y, et al: In vitro synergistic interaction between the cisplatin analogue nedaplatin and the DNA topoisomerase I inhibitor irinotecan and the mechanism of this interaction. Clin Cancer Res 7: 202-209, 2001.

11. Noda K, Ikeda M, Yakushiji M, et al: A phase II clinical study of cis-diammine glycolato platinum, 254-S, for cervical cancer of the uterus. Jpn J Cancer Chemother 19: 885-892, 1992.

12. Okamoto H, Nagatomo A, Kunitoh H, Kunikane H and Watanabe K: A phase I clinical and pharmacologic study of a carboplatin and irinotecan regimen combined with recombinant human granulocyte-colony stimulating factor in the treatment of patients with advanced non-small cell lung carcinoma. Cancer 82: 2166-2172, 1998.

13. Machida S, Ohwada M, Fujiwara H, et al: Phase I study of combination chemotherapy using irinotecan hydrochloride and nedaplatin for advanced or recurrent cervical cancer. Oncology 65: 102-107, 2003.

14. Tsuda H, Hashiguchi Y, Nishimura S, Miyama M, Nakata S, Kawamura $\mathrm{N}$ and Negoro S: Phase I-II study of irinotecan (CPT-11) plus nedaplatin (254-S) with recombinant human granulocyte colony-stimulating factor support in patients with advanced or recurrent cervical cancer. Br J Cancer 91: 1032-1037, 2004.

15. Chitapanarux I, Tonusin A, Sukthomya V, Charuchinda C, Pukanhapan N and Lorvidhaya V: Phase II clinical study of irinotecan and cisplatin as first-line chemotherapy in metastatic or recurrent cervical cancer. Gynecol Oncol 89: 402-407, 2003.

16. Yamamoto K, Iwahana M, Kumazawa E, et al: Antitumor activity of new combination chemotherapy with irinotecan hydrochloride and nedaplatin against human cervical cell lines. Oncol Rep 10: 593-598, 2003. 